\title{
Biochemical Confirmation of the Anti-Inflammatory Effect of Coxibs and their Compositions with N- Acetylgulcosaminil 1-4-N-Acetylmuramoil-L-alanyl-D- Isoglagamin
}

\author{
Syrova Ganna Olegivna $1(\mathbb{D})$, Tishakova Tetyana Stanislavivna ${ }^{*}(\mathbb{D})$, Levashova Olga Leonidivna (D) , \\ Savelieva Olena Valeryivna ${ }^{1}$ (D) \\ 1 Kharkiv National Medical University, 4 Nauky Avenue, Kharkiv, 61022, Ukraine \\ * Correspondence: ttishakova@ukr.net;
}

Scopus Author ID 37028849800

Received: 28.05.2020; Revised: 20.09.2020; Accepted: 26.09.2020; Published: 4.10.2020

\begin{abstract}
The current work is focused on the biochemical confirmation of the anti-inflammatory effect of coxibs and their compositions with licopid as an adjuvant for NSAIDs in the treatment of inflammation. The current investigation aimed to compare the anti-inflammatory effect of rofecoxib, celecoxib, licopid, and pharmaceutical compositions consisting of rofecoxib and licopid, celecoxib, and licopid. Sodium diclofenac was chosen as the reference drug. The anti-inflammatory effect of the test substances was studied using an experimental model of formalin-induced paw edema. The level of SA was determined using SialoTest (SPC Eco-Service). A biochemical study of the anti-inflammatory effect of rofecoxib, celecoxib, licopid, and their composition on the content of inflammation marker (SA) showed that almost all studied drugs reduced the content of SA in rat's blood serum compared to the negative control. The results of the biochemical study showed that rofecoxib has a pronounced antiinflammatory effect. It acts almost 1.2 times better than celecoxib, and the leader in our biochemical studies is a two-component pharmaceutical composition of celecoxib + licopid at the level of SA in blood serum under formalin-induced edema.
\end{abstract}

Keywords: coxibs; biochemical confirmation; anti-inflammatory effect; pharmaceutical composition.

(C) 2020 by the authors. This article is an open-access article distributed under the terms and conditions of the Creative Commons Attribution (CC BY) license (https://creativecommons.org/licenses/by/4.0/).

\section{Introduction}

Pain management is a major global problem according to the statistics of health services and experts. Nonsteroidal anti-inflammatory drugs (NSAIDs) are common medicines that help relieve pain intensity and reduce inflammation caused by tissue damage. Along with inflammatory diseases, they are used in various pathological conditions characterized by acute and chronic pain, primarily in the musculoskeletal system [1,2].

NSAIDs are effective in treating pain and inflammation. They have a unique combination of analgesic, anti-inflammatory, and antipyretic effects. According to their chemical structure, they are divided into the following groups: salicylates, oxycams, coxibs, pyrazolidines, and derivatives of indolocytic, phenylacetic, and propionic acids, as well as alkanones and sulfonamide derivatives [3-5].

Chronic pain is accompanied by the activation of cyclooxygenases (COX)-2 and the formation of a large number of pro-inflammatory prostaglandins. Therefore, selective 
inhibitors (coxibs) demonstrate efficacy associated with inflammation and analgesia. In addition, they tend to accumulate in the site of inflammation. Coxibs' selectivity is the reason for their use in the treatment of osteoarthritis, rheumatoid arthritis, and acute postoperative pain. Thus, we choose COX-2 selective NSAIDs - coxibs for our study. The most important advantage of coxibs is their selectivity that is 2-3 times higher to COX-2 compare to COX-1. This fact is associated with the development of pathology of the gastrointestinal tract (GIT) and a decrease in the synthesis of "cytoprotective" prostaglandins [6-10].

Celecoxib (4-[5-(4-methylphenyl) -3-(trifluoromethyl) -pyrazol- 1-yl] benzenesulfonamide) selectively inhibits $\mathrm{COX}-2$ and blocks the formation of proinflammatory PG. Rofecoxib (4-[4-(methylsulfonyl) phenyl]-3-phenyl-2(5H)-furanone) highly specifically inhibits COX-2 and the formation of anti-inflammatory prostaglandins. At therapeutic concentrations, none of the drugs inhibit COX-1 [11-16].

The complex use of NSAIDs and adjuvant drugs could be essential for treating moderate pain according to the recommendations of the World Health Organization (WHO). In previous work, we studied the effect of caffeine on the analgesic, anti-inflammatory effect of NSAIDs. Our study comprises the biochemical confirmation of the possible use of licopid as an adjuvant for NSAIDs in treating inflammation [17]. The immune-stimulating and additive effect of muramyl dipeptide (MDP), which is an integral component of the cell wall peptidoglycan, was established by a group of French researchers led by E. Lederer back in $1974[18]$.

Our study selected an analog of muramyl dipeptide - licopid (N-acetylglucosaminyl 14-N-acetylmuramyl-L-alanyl-D-isoglugamine) as an adjuvant. As a bacterial immunomodulator, it activates all functions and production of phagocytes as non-specific defense factors (lysozyme, etc.), increases the production of immunoglobulins and proinflammatory interleukins, which initiates the immune response, enhancing antimicrobial protection [19].

\section{Materials and Methods}

The biochemical study of the anti-inflammatory effect was performed on laboratory animals (white WAG-line rats). The current investigation aimed to compare the antiinflammatory effect of rofecoxib, celecoxib, licopid, and pharmaceutical compositions consisting of rofecoxib and licopid, celecoxib, and licopid. Sodium diclofenac (2-(2-(2,6dichlorophenylamino)phenyl)acetic acid) was chosen as the reference drug.

The anti-inflammatory effect of the above substances was studied using an experimental model of formalin-induced paw edema. The animals were divided into 8 treatment groups of 6 animals each. Intact animals of the $1^{\text {st }}$ group and negative control $\left(2^{\text {nd }}\right.$ group) received a single intragastrical dose of $3 \%$ starch mucus $(\mathrm{ml} / \mathrm{g})$. Animals of the $3^{\text {rd }}$ positive control group received reference drug sodium diclofenac $(8 \mathrm{mg} / \mathrm{kg}$, orally). Animals in treatment groups $4-6$ received rofecoxib, celecoxib, and licopid at doses of 1.5, 5, and 0.6 $\mathrm{mg} / \mathrm{kg}$ correspondingly. Animals of group 7 received the composition of rofecoxib $(1.5 \mathrm{mg} / \mathrm{kg})$ with licopid $(0.6 \mathrm{mg} / \mathrm{kg})$. Treatment group 8 received composition of celecoxib $(5 \mathrm{mg} / \mathrm{kg})$ with licopid $(0.6 \mathrm{mg} / \mathrm{kg})$. Formalin solution $(2 \%)$ was injected subcutaneously in the rat's hind paw (groups 3-8).

Formalin-induced paw edema reaches its maximum in 4 hours after modeling. The administration of $3 \%$ starch mucus, reference, and tested drugs was performed 1 hour before maximum swelling taking into account their pharmacokinetic and pharmacodynamic 
characteristics. Animals of all groups were subject to ether anesthesia. Rats were kept in vivarium according to the rules of humane treatment of laboratory animals. The studies were conducted in compliance with the principles of the "European Convention for the Protection of Vertebrate Animals Used for Experimental and other Scientific Purposes" [20] and the Decree of the First National Congress on Bioethics [21].

Sialic acids (SA), N-acetyl, and N-glycyl derivatives of neuraminic acid were used as biochemical indicators to study the anti-inflammatory effect of the tested substances [22]. These compounds are considered normal components of all tissues and biological fluids of the human and animal bodies. They are important components of glycoproteins and glycolipids. After cleavage from glycoproteins, free SAs inactivate many bacterial and viral pathogenic agents. Therefore, an increase in sialoglycoprotein content in the blood can manifest a compensatory, protective inflammatory response.

The SA level was determined using SialoTest (SPC Eco-Service). $1 \mathrm{ml}$ of hydrolyzed reagent, $2 \mathrm{ml}$ of distilled water, and $0.6 \mathrm{ml}$ of serum were added to the tubes. The contents of the tubes were thoroughly mixed and placed in a water bath for 5 minutes. After that, they were centrifuged for 6 minutes at $3000 \mathrm{rpm}$. To the collected supernatant $(2 \mathrm{ml})$ were added $0.4 \mathrm{ml}$ of a color-coagulating reagent, incubated in a boiling water bath for 15 minutes, cooled in cold water, then $2 \mathrm{ml}$ of distilled water was added and stirred. The optical density (OD) was measured against distilled water.

The formula calculated the content of the SA:

$$
\mathrm{C}_{\mathrm{SA}}=\frac{\frac{E_{\text {opt }} \cdot C_{c a l}}{E_{c a l}} \mathrm{mmol} / \mathrm{L} .}{\text {. }}
$$

The analysis was performed on a photoelectric colorimeter CPC-3 at a wavelength of $540 \mathrm{~nm}$ and a cuvette optical path length of $10 \mathrm{~mm}$. The conversion factor $(\mathrm{K})$ was determined before measuring the samples: the optical density ( $\left.\mathrm{E}_{\mathrm{cal}}\right)$ of the calibrator was measured on the device against distilled water. The formula calculated the conversion factor: $K=2 / \mathrm{E}$, where 2 is the concentration of sialic acids in the calibrator $(\mathrm{mmol} / \mathrm{L})$. Statistical processing of the results was performed using the software package Statistics 6.0. The reliability of the obtained results was established using Student's t-test.

\section{Results and Discussion}

The level of SA in the blood serum of rats in the negative control reaches $3.508 \pm 0.03$ $\mathrm{mmol} / \mathrm{L}$ (group 2), which is almost 1.5 times greater than the intact control (group 1) showed.

A biochemical study of the anti-inflammatory effect of rofecoxib, celecoxib, licopid, and their composition on the content of inflammation marker (SA) showed that almost all studied drugs reduced the content of SA in rat's blood serum compare to the negative control (groups 3-8), see Table 1.

Table 1. Anti-inflammatory effect of rofecoxib, celecoxib, licopid, and their composition on the content of SA in rats' blood serum under the condition of formalin-induced paw edema.

\begin{tabular}{c|c|c} 
№ & Treatment groups $(\mathbf{n}=\mathbf{6})$ & SA, mmol/L \\
\hline 1. & Intact & $2.471 \pm 0.06$ \\
\hline 2. & Negative control & $3.508 \pm 0.03^{1}$ \\
\hline 3. & $\begin{array}{c}\text { Positive control } \\
\text { (sodium diclofenac + formalin edema) }\end{array}$ & $2.68 \pm 0.04^{2 / 3 / 5 / 7}$ \\
\hline 4. & Rofecoxib + formalin edema & $2.891 \pm 0.01^{2 / 4 / 5 / 7}$ \\
\hline 5. & Celecoxib+ formalin edema & $3.07 \pm 0.02^{1 / 7 / 8}$ \\
\hline 6. & Licopid + formalin edema & $3.2 \pm 0.01^{1 / 7 / 8}$ \\
\hline
\end{tabular}




\begin{tabular}{c|c|c}
\hline № & Treatment groups (n=6) & SA, mmol/L \\
\hline 7. & Rofecoxib + licopid + formalin edema & $2.79 \pm 0.03^{2 / 5 / 7 / 8}$ \\
\hline 8. & Celecoxib + licopid + formalin edema & $2.16 \pm 0.11^{2 / 3 / 4 / 5 / 6 / 8}$ \\
Note 1. (mean \pm error in mean) $)^{1}-$ the difference is significant compared to the intact group, $\mathrm{P}<0.05 ;$ \\
Note 2. (mean \pm error in mean) $)^{2}-$ the difference is significant compared to the negative control (formalin-induced paw edema), $\mathrm{P}<0.05 ;$ \\
Note 3. (mean \pm error in mean) $)^{3}-$ the difference is significant compared to mono-administration of rofecoxib, $\mathrm{P}<0.05 ;$ \\
Note 4. (mean \pm error in mean) $)^{4}-$ the difference is significant compared to mono-administration of celecoxib, $\mathrm{P}<0.05 ;$ \\
Note 5. (mean \pm error in mean) $)^{5}-$ the difference is significant compared to mono-administration of licopid, $\mathrm{P}<0,05 ;$ \\
Note 6. (mean \pm error in mean) $)^{6}-$ the difference is significant compared to rofecoxib + licopid composition, $\mathrm{P}<0.05 ;$ \\
Note 7. (mean \pm error in mean) $)^{7}-$ the difference is significant compared to celecoxib + licopid composition, $\mathrm{P}<0.05 ;$ \\
Note 8. (mean \pm error in mean) $)^{8}-$ the difference is significant compared to the positive control (reference drug), $\mathrm{P}<0.05$.
\end{tabular}

Mono-administration of rofecoxib (group 4) comprises $2.891 \pm 0.01 \mathrm{mmol} / \mathrm{L}$. The result shows a decrease in the SA content 1.3 times in rats' blood serum compared with the negative control group and approached the positive control.

The results of the celecoxib mono-administration (group 5) comprise $3.07 \pm 0.02$ $\mathrm{mmol} / \mathrm{L}$. It indicates only a tendency to reduce the level of SA in the serum of rats relative to formalin-induced paw edema.

Mono-administration of licopid (group 6) gives a tendency to a decrease in the level of $\mathrm{SA}$ in rat serum, relative to formalin-induced paw edema (group 2).

The composition of licopid with rofecoxib (group 7) shows a tendency to decrease the SA content in rat's blood serum compared to mono-administration of rofecoxib but did not reach the reference drug data (gr. 3).

The composition of licopid with celecoxib (group 8) contributed to an effective decrease in the SA content in rat's blood serum under formalin-induced paw edema conditions. This composition shows similar results with the positive control (reference drug, group 3). It was not statistically significantly different from the intact group 1, i.e., licopid effectively potentiates the anti-inflammatory effect of celecoxib.

\section{Conclusions}

The biochemical study of the coxibs anti-inflammatory effect on the SA level in the rat's serum of rofecoxib and celecoxib indicate that rofecoxib has the pronounced antiinflammatory effect of the tested drugs. It acts almost 1.2 times better than celecoxib.

The immunostimulant - licopid tends to decrease SA level in rat serum relative to formalin-induced paw edema conditions.

The leader in our biochemical studies is a two-component pharmaceutical composition of celecoxib + licopid at the level of SA in blood serum under formalin-induced edema, which reduces the level of SA (inflammation marker) compare to a level of intact control. It works better than the positive control (reference drug).

\section{Funding}

This research received no external funding.

\section{Acknowledgments}

This research has no acknowledgment.

\section{Conflicts of Interest}

We know of no conflicts of interest associated with publication. 


\section{References}

1. Herren-Gerber, R.; Weiss, S.; Arendt-Nielsen, L.; Petersen-Felix, S.; Stefano, G.D.; Radanov, B.P.; Curatolo, M. Modulation of central hypersensitivity by nociceptive input in chronic pain after whiplash injury. Pain Med. 2004, 5, 366-376, https://doi.org/10.1111/j.1526-4637.2004.04055.x

2. Naumov. A.V.; Khovasova, N.O.; Moroz, V.I.; Tkacheva, O.N. Falls and pathology of the musculoskeletal system in the older age groups. Zhurnal Nevrologii i Psikhiatrii Imeni S.S. Korsakova 2020, 120(2), 7-14 [In Russian] DOI: 10.17116/jnevro20201200217

3. Blanca-Lopez, N.; Somoza-Alvarez, M.L.; Bellon, T.; Amo, G.; Canto, G.; Blanca, M. NSAIDs hypersensitivity: questions not resolved. Curr. Opin. Allergy Clin. Immunol. 2018, 18, 291-301. https://doi.org/10.1097/ACI.0000000000000454

4. Shostak, N.A.; Klimenko, A.A. Nonsteroidal Anti-Inflammatory Drugs: Current Aspects of Their Use Klinicist 2013, 7, 53-61. https://doi.org/10.17650/1818-8338-2013-3-4-53-61

5. Goudas, L.; Carr, D.B.; Bloch, R. Management of cancer pain. Evidence Report/Technology Assessment No. 35 (prepared by the New England Medical Center Evidence-Based Practice Center under Contract No 290-97-0019). AHRQ Publication No. 02-E002. 2001.

6. Sinatra, R. Role of COX-2 Inhibitors in the Evolution of Acute Pain Management. J. Pain Symptom Manage. 2002, 24, S18-S27, https://doi.org/10.1016/S0885-3924(02)00410-4

7. Mannion, R.J.; Woolf, C.J. Pain mechanisms and management: a central perspective. The Clinical journal of pain 2000, 16, S144-S156, https://doi.org/10.1097/00002508-200009001-00006.

8. Pannunzio, A; Coluccia, M. Cyclooxygenase-1 (COX-1) and COX-1 Inhibitors in Cancer: A Review of Oncology and Medicinal Chemistry Literature. Pharmaceuticals 2018, 11, 101. doi:10.3390/ph11040101

9. Stephens, J.M.; Pashos, C.L.; Haider, S.; Wong, J.M. Making Progress in the Management of Postoperative Pain: A Review of the Cyclooxygenase 2-Specific Inhibitors. Pharmacotherapy: The Journal of Human Pharmacology and Drug Therapy 2004, 24, 1714-1731, https://doi.org/10.1592/phco.24.17.1714.52339

10. Stephens, J.M.; Pashos, C.L.; Haider, S.; Wong, J.M. Making Progress in the Management of Postoperative Pain: A Review of the Cyclooxygenase 2-Specific Inhibitors. Pharmacotherapy: The Journal of Human Pharmacology and Drug Therapy 2004, 24, 1714-1731, https://doi.org/10.1592/phco.24.17.1714.52339

11. Morrison, B.W.; Christensen, S.; Yuan, W.; Brown, J.; Amlani, S.; Seidenberg, B. Analgesic efficacy of the cyclooxygenase-2-specific inhibitor rofecoxib in post-dental surgery pain: a randomized, controlled trial. Clin. Ther. 1999, 21, 943-953, https://doi.org/10.1016/S0149-2918(99)80016-2

12. Jiang, M.; Deng, H.; Chen, X. et al. The efficacy and safety of selective COX-2 inhibitors for postoperative pain management in patients after total knee/hip arthroplasty: a meta-analysis. J Orthop Surg Res 2020, 15, 39. https://doi.org/10.1186/s13018-020-1569-z

13. Kurita Varoli, F.; Sucena Pita, M.; Sato, S.; Issa, J.P.M.; do Nascimento, C.; Pedrazzi, V. Analgesia evaluation of 2 NSAID drugs as adjuvant in management of chronic temporomandibular disorders. The Scientific World Journal 2015, 2015, https://doi.org/10.1155/2015/359152

14. Schug, S.A. The role of COX-2 inhibitors in the treatment of postoperative pain. J. Cardiovasc. Pharmacol. 2006, 47, S82-S86, https://doi.org/10.1097/00005344-200605001-00015.

15. Nan, Li; Jian, Wu; Zhou, T; Congyou, Gu; , Cai1; Huaiyong, Gan;Zhenzhong, Feng. Celecoxib inhibits endometrial cancer cells through COX-2-dependent and non-dependent pathways. Int J Clin Exp Med 2019, 12(5), 4707-4716. www.ijcem.com /ISSN:1940-5901/IJCEM0083034

16. Issioui, T.; Klein, K.W.; White, P.F.; Watcha, M.F.; Coloma, M.; Skrivanek, G.D.; Jones, S.B.; Thornton, K.C.; Marple, B.F. The efficacy of premedication with celecoxib and acetaminophen in preventing pain after otolaryngologic surgery. Anesth. Analg. 2002, 94, 1188-1193, https://doi.org/10.1097/00000539200205000-00025

17. Syrova, G; Lukianova, L.; Sinelnik, V.; Krasnikova, Yu.; Salam, L. Experimental investigation of the effect of pharmaceutical composition on the central nervous system. Inter collegas: theoretical \& experimental medicine 2019, 6 (3), 162-167. https://doi.org/10.35339/ic.6.3.162-167

18. Martinon, F.; Agostini, L; Meylan, E; Tschopp, J. Identification of Bacterial Muramyl Dipeptide as Activator of the NALP3/Cryopyrin Inflammasome Current Biology 2004, 14, 1929-1934, https://doi.org/10.1016/j.cub.2004.10.027

19. Feshchenko, Y. I., Iashyna,L. A., Ishchuk,S. G., Matviyenko Y. A. Immunostimulator licodid and it's possibilities in pulmonology Astma and allergy 2012, 1, 61-65. (In Russian). Available at: http://www.ifp.kiev.ua/doc/journals/aa/12/pdf12-1/61.pdf 
20. European Convention for the protection of vertebrate animals used for experimental and other scientific $\begin{array}{lllll}\text { purposes } & \text { (1986). } & \text { ETS } & \text { No. } & \text { Strasbourg. }\end{array}$ at: http://conventions.coe.int/treaty/en/treaties/html/123.htm

21. Reznikov, O.H. (2003). Zahalni etychni pryntsypy eksperymentiv na tvarynakh General ethical principles of animal experiments Endokrynolohiia. Endocrynology 2003, 8,142-145 [in Ukrainian].

22. Zhang, C; Chen, J; Liu, Y; et al. Sialic acid metabolism as a potential therapeutic target of atherosclerosis. Lipids Health Dis 2019, 18, 173. https://doi.org/10.1186/s12944-019-1113-5 